\title{
EFEITO DE PORTA-ENXERTOS E ESPAÇAMENTOS ENTRE PLANTAS NA QUALIDADE DE PÊSSEGOS 'AURORA-1'1
}

\author{
CAROLINAMATHIAS ${ }^{2}$, NEWTON ALEX MAYER ${ }^{3}$, BEN-HUR MATTIUZ $^{4}$, FERNANDO MENDES PEREIRA $^{5}$
}

RESUMO - O objetivo deste trabalho foi avaliar a qualidade pós-colheita de pêssegos da cultivar 'Aurora-1' enxertada sobre quatro porta-enxertos: 'Okinawa' propagado por sementes e por estacas herbáceas, Clone 15 e cv. Rigitano de umezeiro propagados por estacas herbáceas, e conduzidos em três espaçamentos: 6 × $2 \mathrm{~m}, 6 \times 3 \mathrm{~m} \mathrm{e} 6 \times 4 \mathrm{~m}$. Os frutos foram colhidos na safra de 2005, obedecendo ao estádio de maturação correspondente à coloração exigida para a comercialização in natura, eliminando-se os defeituosos, machucados ou fora do padrão de maturação estipulado. Foram realizadas análises físicas (massa fresca do fruto, diâmetro longitudinal, diâmetro equatorial, coloração externa, coloração interna e firmeza) e químicas dos frutos (sólidos solúveis, acidez titulável e índice de maturação). Os porta-enxertos e os espaçamentos estudados não influenciaram na coloração externa, no ângulo de cor e na luminosidade do mesocarpo, na firmeza e na acidez dos pêssegos 'Aurora-1'. Pêssegos 'Aurora-1' apresentaram maior massa fresca, diâmetro longitudinal e diâmetro equatorial, quando produzidos no Clone 15 e na cv. Rigitano de umezeiro como porta-enxerto. O uso do Clone 15 de umezeiro como porta-enxerto induziu à produção de frutos com maior teor de sólidos solúveis e melhor índice de maturação (gosto), em relação ao 'Okinawa' propagado por estacas herbáceas. O maior espaçamento entre plantas (6 x 4 m) induziu à produção de pêssegos menores, entretanto com maior teor de sólidos solúveis e melhor relação SS/AT.

Termos para indexação: Prunus persica, Prunus mume, porta-enxerto, composição química.

\section{EFFECT OF ROOTSTOCKS AND TREE SPACING ON ‘AURORA-1’ PEACH QUALITY}

ABSTRACT - The objective this research was to evaluate the post harvest 'Aurora-1' peaches quality, budded on four rootstocks ('Okinawa' propagated by seeds and herbaceous cuttings, Clone 15 and 'Rigitano' mume propagated by herbaceous cuttings), cultivated in three spacing: $6 \times 2 \mathrm{~m}, 6 \times 3 \mathrm{~m}$ and $6 \times 4 \mathrm{~m}$. Fruits harvest was realized in 2005, based on peel colors, which is the demand for in natura commercialization, corresponding to the maturation indexes. Fruit physical attributes like fruit fresh weight, longitudinal and equatorial diameter, firmness, external and internal color and chemical evaluations (soluble solids, acidity contents and ratio) were analyzed. Through the obtained data, it was verified that rootstocks and tree spacing did not influence the external color, hue and internal lightness mesocarp, the firmness and acidity contents of 'Aurora-1' peaches. The highest fruit fresh weight, longitudinal and equatorial diameters were obtained on Clone 15 and 'Rigitano' mume rootstock. 'Aurora-1' peach trees budded on Clone 15 mume rootstocks have got the highest soluble solids contents and ratio than 'Okinawa' propagated by herbaceous cuttings. 'Aurora-1' peach trees cultivated in $6 \times 4 \mathrm{~m}$ space produced shorter fruits, but with the highest soluble solids contents and ratio.

Index terms: Prunus persica, Prunus mume, rootstocks, chemical composition.

\section{INTRODUÇÃO}

O pêssego [Prunus persica $($ L.) Batsch] é a oitava fruta mais produzida no mundo e uma das mais consumidas in natura. A produção mundial de pêssegos e de nectarinas, em 2004, foi de 15.346.666 toneladas (Fao, 2007). No Brasil, apesar de se ter 23.864 hectares de área colhida com pêssegos (Agrianual, 2007), a produção é insuficiente para o abastecimento interno (Sato, 2001), devido, principalmente, à sazonalidade da produção, à baixa produtividade, problemas de logística e à alta perecibilidade dos frutos.

Em 2005, o Brasil importou 7.068 toneladas de pêssegos frescos e 2.944 toneladas de pêssegos em calda, oriundos principalmente da Argentina (62,04\% e 98,74\%, respectivamente).
Naquele ano, não houve registro de nenhuma exportação significativa de pêssegos brasileiros (Agrianual, 2007).

Além de a produção ser sazonal e insuficiente para abastecimento interno, verifica-se que a produtividade média da persicultura brasileira é baixa. Segundo dados da Fao (2007), o Brasil ocupa o $11^{\circ}$ lugar no mundo em área colhida com pessegueiro e nectarineira. Entretanto, a produtividade média brasileira, no ano de 2005, foi de apenas 10,0 tha ${ }^{-1}$, o que coloca o País na $21^{\text {a }}$ colocação dentre os de maior produtividade e abaixo da média mundial, que foi de 10,99 tha ${ }^{-1} \mathrm{em} 2004$. Como alternativa a este problema, observa-se que o adensamento dos pomares pode contribuir de forma significativa, tecnologia já bastante estudada e consolidada no Brasil na cultura da macieira, viabilizada principalmente com o uso de porta-enxertos clonais

${ }^{1}$ (Trabalho 087-07). Recebido em 30-03-2007. Aceito para publicação em: 09-11-2007. Apoio Financeiro: FAPESP (Processos n ${ }^{\text {os }}$ 04/12110-6 e 05/ 50157-7).

${ }^{2}$ Eng. Agr., Depto. de Tecnologia da UNESP/FCAV. E-mail: krolina_mth@yahoo.com.br.

${ }^{3}$ Eng. Agr., Dr., Pesquisador da Embrapa Clima Temperado, Rodovia BR 392, km 78, Caixa Postal 403, CEP 96001-970, Pelotas-RS. E-mail: alex@cpact.embrapa.br.

${ }^{4}$ Eng. Agr., Dr., Professor do Departamento de Tecnologia da Universidade Estadual Paulista. UNESP/FCAV, Câmpus de Jaboticabal. Via de Acesso Prof Paulo Donato Castellane, s/n. CEP 14884-900. Jaboticabal-SP. E-mail: benhur@fcav.unesp.br.

${ }^{5}$ Eng. Agr., Dr., Professor Titular Voluntário do Depto. de Produção Vegetal da UNESP/FCAV. E-mail: inagrojab@yahoo.com.br. 
anões.

Constata-se que a persicultura brasileira carece de informações sobre adensamento de pomares, uso de portaenxertos de baixo vigor e seus efeitos sobre a qualidade física e química dos frutos produzidos. O uso de clones de umezeiro (Prunus mume Sieb. et Zucc.), como porta-enxertos de pessegueiro, tem revelado promissoras perspectivas de sucesso.

As características pós-colheita dos frutos estão intimamente ligadas à escolha do porta-enxerto, da cultivar-copa e do manejo adotado na implantação e na condução do pomar. De acordo com pesquisas recentes, o porta-enxerto exerce influência tanto sobre aspectos físicos quanto na composição química dos frutos, promovendo alterações na altura, diâmetro, coloração, teores de sólidos solúveis e de acidez titulável (FornerGiner et al., 2003; Al-Jaleel et al., 2005; Perez-Perez et al., 2005). O grau de excelência de um produto, bem como a sua aceitação pelo consumidor, está relacionado aos seus atributos de qualidade que, em frutas e hortaliças in natura, engloba a aparência, os atributos sensoriais, o valor nutritivo, os constituintes químicos e as propriedades funcionais (Kader, 2002)

O objetivo deste trabalho foi avaliar a qualidade póscolheita de pêssegos da cultivar 'Aurora-1' enxertada sobre quatro porta-enxertos e conduzida em três espaçamentos.

\section{MATERIAL E MÉTODOS}

Foram produzidas mudas de pessegueiro [Prunus persica (L.) Batsch] da cv. Aurora-1 (Ojima et al., 1989), por meio de enxertia de borbulhia em escudo modificada (Pereira \& Mayer, 2005). Os porta-enxertos utilizados foram a cv. Okinawa [Prunus persica (L.) Batsch], propagada por germinação de sementes e por enraizamento de estacas herbáceas, o Clone 15 e a cv. Rigitano (Pereira et al., 2007) de umezeiro (Prunus mume Sieb. et Zucc.), ambos propagados por enraizamento de estacas herbáceas.

Após o preparo do solo (Pereira et al., 2002), as mudas foram transplantadas no local definitivo, em agosto de 2003, em área experimental na Fazenda Santa Alzira, localizada no Município de Vista Alegre do Alto-SP. O solo da região é classificado como Argissolo Vermelho-Amarelo eutrófico de textura arenosa média (Oliveira et al., 1999). Foram adotados três espaçamentos entre plantas: $6 \times 2 \mathrm{~m}, 6 \times 3 \mathrm{me} 6 \times 4 \mathrm{~m}$. A condução do pomar, os tratos culturais e a irrigação por microaspersão foram realizados conforme recomendações de Pereira et al. (2002) para a cultura do pessegueiro na região. As plantas foram conduzidas em forma de taça, de forma a ocupar da melhor maneira possível o espaço disponível em cada espaçamento entre plantas estudado. Desta forma, no menor espaçamento, o formato da taça foi mais fechado do que no espaçamento de $6 \times 4 \mathrm{~m}$. O número de pernadas principais foi praticamente o mesmo entre os espaçamentos (entre 5 e 9, no menor espaçamento; entre 6 e 11, no intermediário; e entre 6 e 10, no maior espaçamento).

A colheita dos frutos foi realizada em novembro de 2005 (2 anos e 3 meses após transplantio das mudas), entre 80 e 90 dias após plena floração, obedecendo ao estádio de maturação correspondente à coloração exigida para a comercialização in natura, segundo as normas do Programa Brasileiro de Classificação de pêssego e nectarina (CQH-CEAGESP, 1998). Após a colheita, os frutos foram acondicionados em caixas de papelão e transportados rápida e cuidadosamente ao laboratório de Tecnologia dos Produtos Agrícolas da FCAV/UNESP, Câmpus de Jaboticabal-SP, que dista $50 \mathrm{~km}$ do local da colheita. Esses frutos foram submetidos à nova seleção, visando a dar o máximo de uniformidade às parcelas, através da eliminação de todos os defeituosos, machucados ou diferentes do estádio de maturação estipulado.

Foram realizadas análises físicas dos frutos, referentes à massa fresca (g), diâmetro longitudinal ( $\mathrm{mm})$, diâmetro equatorial $(\mathrm{mm})$, firmeza dos frutos $(\mathrm{N})$, coloração externa ou do epicarpo e coloração interna ou do mesocarpo, expressas por valores de luminosidade (L), ângulo de cor (Hue) e cromaticidade (C) (Minolta Corp, 1994). Foram também realizadas análises químicas de conteúdo de sólidos solúveis (SS), expressos em ${ }^{\circ}$ Brix, e da acidez titulável (AT), expressa em equivalente de g de ácido cítrico 100${ }^{1} \mathrm{~g}$, conforme metodologias descritas pela AOAC (1997). Além disso, foi realizada a relação de ambas (SS/AT), parâmetro conhecido como índice de maturação (Chitarra \& Chitarra, 2005). A análise dos dados foi realizada segundo delineamento inteiramente casualizado, em esquema fatorial $4 \times 3$. O fator portaenxerto foi composto por quatro níveis ('Okinawa' propagado por sementes e por estacas herbáceas, Clone 15 e cv. Rigitano de umezeiro propagados por estacas herbáceas) e o fator espaçamento de plantio foi composto por três níveis $(6 \times 2 \mathrm{~m}, 6 \mathrm{x}$ $3 \mathrm{~m}$ e $6 \times 4 \mathrm{~m}$ ), totalizando doze tratamentos, com 4 repetições. No campo, cada parcela foi constituída por 6; 4 e 3 plantas, para os espaçamentos de 6 × 2 m, 6 × 3 m e 6 × 4 m, respectivamente. De cada parcela, foram selecionados quatro frutos para as análises. Os dados obtidos foram submetidos à análise de variância, por meio do teste $\mathrm{F}$, e as médias comparadas entre si, mediante o teste de Tukey, ao nível de $5 \%$ de probabilidade, utilizando-se do software ESTAT (Estat, 1994).

\section{RESULTADOS E DISCUSSÃO}

Houve diferença estatística significativa entre os portaenxertos estudados na massa fresca dos frutos (Tabela 1). Os frutos com maior massa foram obtidos em plantas enxertadas sobre o Clone 15, seguido da cv. Rigitano. Entre os métodos de propagação utilizados para o 'Okinawa', não houve diferença significativa. Estes resultados concordam com Campo Dall'Orto et al. (1992), que já haviam constatado que pessegueiros enxertados em umezeiro, propagado por sementes, produziram frutos com maior massa, em relação aos produzidos em 'Okinawa'. Denardi \& Spengler (2001) também verificaram influência do portaenxerto no aumento da massa em maçãs, ao relatarem que macieiras 'Fuji', enxertadas sobre o porta-enxerto 'M-9', produziram frutos com maior massa $(159,2 \mathrm{~g})$, comparativamente às produzidas com o uso do 'M-7' (135,5 g) e do 'MM-111' (131,2 g).

Quanto ao diâmetro longitudinal dos frutos, resultado significativamente superior foi verificado para o porta-enxerto Clone 15 (Tabela 1). Ambos os métodos de propagação do 'Okinawa' estudados induziram ao menor diâmetro longitudinal 
dos frutos. Para o diâmetro equatorial dos frutos, também se observa efeito positivo no uso dos porta-enxertos de umezeiro, pois estes induziram à produção de frutos com maior diâmetro equatorial, sendo diferentes estatisticamente daqueles produzidos sobre 'Okinawa' propagado por semente ou por estacas herbáceas (Tabela 1). Denardi \& Spengler (2001) comprovaram que macieiras 'Fuji', enxertadas sobre o porta-enxerto 'M-9', induziram aumento na produção e desenvolveram frutos com maior diâmetro equatorial do que plantas enxertadas sobre o 'M-7' ou 'MM-111'.

Com relação ao espaçamento, para a variável massa fresca do fruto, observa-se que as plantas conduzidas no espaçamento $6 \times 3 \mathrm{~m}$ apresentaram frutos com maior massa do que os provenientes do espaçamento $6 \times 4 \mathrm{~m}$, enquanto plantas no menor espaçamento $(6 \times 2 \mathrm{~m})$ produziram frutos com massa média intermediária (Tabela 1). Frutos oriundos do maior espaçamento $(6 \times 4 \mathrm{~m})$ poderiam apresentar maior massa, em função da menor competição por luz solar, permitindo melhores condições de desenvolvimento, mas esse fato não foi comprovado. Segundo Barbosa et al. (2000), a cv. Aurora-1 foi uma das que melhor se adaptaram ao sistema de pomar compacto, mantido no espaçamento de 4 x 1,5 m (1.667 plantas.ha $\left.{ }^{-1}\right)$. Pessegueiros da cv. Delicioso Precoce (IAC 5174-14), enxertados sobre a ameixeira 'Kelsey Paulista' e conduzidos no espaçamento $2 \times 0,5 \mathrm{~m}$, tiveram alta produção de frutos graúdos (Campo Dall'Orto et al., 1988), demonstrando o ganho de massa nos frutos de plantas produzidas em pomares de alta densidade.

Os diâmetros longitudinal e equatorial dos frutos foram influenciados pelos espaçamentos de plantio estudados (Tabela 1). No espaçamento $6 \times 4 \mathrm{~m}$, foram produzidos frutos com menores valores para estas duas variáveis. Esses dados revelam efeito benéfico da redução do espaçamento entre plantas, quando cultivadas em regiões de clima mais quente, como a região de Jaboticabal-SP, pois, além do potencial para maiores produtividades, também há benefício em relação à qualidade física do fruto, aumentando seu valor comercial. O maior tamanho da fruta é fator determinante para a obtenção de melhores preços (Almeida, 2006).

Com relação à coloração externa do fruto, não houve efeito significativo, tanto dos porta-enxertos como dos espaçamentos estudados (Tabela 2). Esses resultados contrariam Campo Dall'Orto et al. (1992), que verificaram aumentos na porcentagem de vermelho da película de pêssegos oriundos de plantas enxertadas em umezeiro, em relação às plantas enxertadas em 'Okinawa'. A melhoria da coloração externa das frutas é um efeito desejável, pois a aparência é um dos fatores que responde por 83 $\%$ para a aquisição de um produto pelo consumidor (Kader, 2002). A cor de recobrimento dos pêssegos desenvolve-se com o avanço da maturação e é influenciada pela maior ou menor exposição ao sol, sendo recomendada a realização de poda verde e raleio para uma boa exposição das frutas aos raios solares. Segundo Denardi \& Spengler (2001), maçãs 'Fuji', enxertadas sobre 'M-9', tiveram maior acúmulo de pigmentos (mais coloridos), fato este atribuído à formação de uma copa compacta com ramos curtos, o que promove melhor exposição dos frutos ao sol.

Nas análises da coloração interna dos frutos (Tabela 2), foi possível verificar que tanto os porta-enxertos quanto os espaçamentos estudados não afetaram significativamente a luminosidade e o ângulo de cor. Entretanto, para a cromaticidade, o porta-enxerto 'Rigitano' induziu a produção de frutos com maior cromaticidade em relação às plantas enxertadas sobre 'Okinawa', porém não diferiu estatisticamente dos frutos produzidos sobre $o$ Clone 15. Frutos com valores altos deste índice indicam maior acúmulo de pigmentos carotenóides, provavelmente devido à melhor qualidade da luz incidente (comprimento de onda) sobre os frutos ao longo do desenvolvimento (Kader, 2002). Também houve diferença significativa entre os espaçamentos testados para esta variável, pois, nos menores espaçamentos $(6 \times 2 \mathrm{~m}$ e 6 x $3 \mathrm{~m}$ ), os frutos apresentaram maior cromaticidade (Tabela 2).

A firmeza dos frutos não foi afetada pelos porta-enxertos e espaçamentos (Tabela 3). Este resultado revela que, provavelmente, a longevidade pós-colheita de pêssegos produzidos com o uso do umezeiro como porta-enxerto, bem como sua condução em pomares adensados, não será significativamente afetada. Giorgi et al. (2005) constataram que a firmeza de pêssegos da cv. Suncrest não foi significativamente afetada pelos porta-enxertos, com exceção das plantas enxertadas sobre 'Barrier 1', que apresentaram frutos mais firmes. Tsipouridis $\&$ Thomidis (2005), ao testarem o efeito de 14 diferentes portaenxertos na qualidade de pêssegos 'May Crest', observaram que plantas enxertadas em 'GF 677' e 'Loadel' propiciaram maior firmeza aos frutos, quando comparados aos demais porta-enxertos.

Houve efeito significativo dos porta-enxertos no teor de sólidos solúveis (SS) dos frutos (Tabela 3). Quando utilizados os porta-enxertos Clone 15 e cv. Rigitano de umezeiro, há produção de frutos com maior teor de sólidos solúveis do que quando enxertadas em 'Okinawa' propagado por estacas herbáceas. Nessa variável, os porta-enxertos 'Okinawa' de semente e a cv. Rigitano não diferem significativamente entre si. Esses dados comprovam que o uso do umezeiro como porta-enxerto é bastante promissor, pois aumenta o teor de sólidos solúveis, tornando os frutos mais atrativos ao consumo in natura, concordando com Campo Dall'Orto et al. (1994). Com relação ao espaçamento (Tabela 3), observou-se que este afetou o teor de sólidos solúveis de forma diretamente proporcional, ou seja, no maior espaçamento $(6 \times 4$ $\mathrm{m})$, os frutos apresentaram teor mais elevado de sólidos solúveis (13,14 ${ }^{\circ}$ Brix $)$ e, no espaçamento de 6 × 2 m, o menor teor de sólidos solúveis $\left(11,81{ }^{\circ} \mathrm{Brix}\right)$. Provavelmente, a maior exposição das plantas aos raios solares, proporcionada pelo formato mais aberto da taça no maior espaçamento, tenha aumentado a taxa fotossintética e, com isso, também aumentado o acúmulo de sólidos solúveis nos frutos. Segundo Giorgi et al. (2005), os pêssegos das plantas enxertadas sobre 'Citation' tiveram teor mais elevado de sólidos solúveis, quando comparados aos demais portaenxertos estudados. Castle (1995) também observou a influência dos porta-enxertos na variação do teor de sólidos solúveis em maçãs, pois verificou que a cv. Empire, quando enxertada em 'M.27', produziu frutos com teor mais elevado de sólidos solúveis, quando comparado aos porta-enxertos 'M.26' e 'M.9'. Campo Dall'Orto et al. (1992) constataram que o uso do umezeiro como porta-enxerto promove o aumento do teor de sólidos solúveis em pêssegos e que, pelo menor vigor da espécie, o umezeiro pode ser utilizado como porta-enxerto de pessegueiro em pomares 
adensados.

A acidez titulável (AT) não foi significativamente afetada pelos porta-enxertos e espaçamentos testados (Tabela 3). Em maçãs cv. Goldspur, Castle (1995) verificou maior acidez quando utilizado o porta-enxerto 'M.26', comparativamente às maçãs produzidas sobre 'MM.111'.

A relação entre os teores de SS e AT, conhecida como índice de maturação, é um importante parâmetro qualitativo, pois indica o gosto do produto, uma vez que é o resultado do balanceamento entre estes constituintes. Na Tabela 3, pode-se observar que houve influência dos porta-enxertos nesta relação. Os porta-enxertos de umezeiro propiciaram os melhores resultados, com destaque para o Clone 15, que apresentou frutos com maior índice de maturação em relação aos produzidos no 'Okinawa' de estaca herbácea. Os espaçamentos também interferiram nesta relação (Tabela 3), sendo que as plantas conduzidas nos maiores espaçamentos $(6 \times 3 \mathrm{~m} \mathrm{e} 6 \times 4 \mathrm{~m})$ desenvolveram frutos com melhor relação SS/AT, ou seja, frutos com melhor gosto. Os açúcares, dentre os constituintes químicos, são responsáveis pela cor atrativa, pela textura, quando combinados com polissacarídeos estruturais, e pela doçura, influenciando no sabor através do balanço com os ácidos (Chitarra \& Chitarra, 2005).

Durante o crescimento dos frutos, o ganho de peso e o aumento do diâmetro são influenciados por fatores climáticos, de manejo (raleio, adubação e irrigação) e também pelos portaenxertos. Em uma mesma planta, são encontrados pêssegos com tamanho e estádio de maturação variados, e as frutas que recebem maior exposição solar, acumulam maior quantidade de açúcares. O alto conteúdo de ácidos também interfere na qualidade final do produto, pois afeta a doçura. Durante o amadurecimento, ocorre a redução da acidez, e a fruta passa a ter sabor mais agradável, devendo-se, por este motivo, sempre considerar a relação SS/AT no momento da colheita (Campo Dall'Orto et al., 1992; Campo Dall'Orto et al., 1994).

TABELA 1 - Características físicas de pêssegos da cultivar Aurora-1, em função do porta-enxerto e do espaçamento entre plantas. Vista Alegre do AltoSP, 2005.

\begin{tabular}{cccc}
\hline Porta-enxerto & Massa do fruto $(\mathrm{g})$ & Diâmetro longitudinal $(\mathrm{mm})$ & Diâmetro equatorial $(\mathrm{mm})$ \\
\hline 'Okinawa' semente & $97,98 \mathrm{c}$ & $68,19 \mathrm{c}$ & $57,88 \mathrm{~b}$ \\
'Okinawa' estaca herbácea & $103,04 \mathrm{c}$ & $69,82 \mathrm{bc}$ & $58,37 \mathrm{~b}$ \\
'Rigitano' & $115,72 \mathrm{~b}$ & $70,31 \mathrm{~b}$ & $60,80 \mathrm{a}$ \\
Clone 15 & $127,58 \mathrm{a}$ & $72,30 \mathrm{a}$ & $62,18 \mathrm{a}$ \\
\hline Fporta-enxerto & $81,1081^{* *}$ & $14,0339^{* *}$ & $28,6513^{* *}$ \\
\hline Espaçamento & & & \\
\hline $6 \times 2 \mathrm{~m}$ & $111,29 \mathrm{ab}$ & $71,61 \mathrm{a}$ & $60,06 \mathrm{a}$ \\
$6 \times 3 \mathrm{~m}$ & $113,80 \mathrm{a}$ & $70,70 \mathrm{a}$ & $60,54 \mathrm{a}$ \\
$6 \times 4 \mathrm{~m}$ & $108,14 \mathrm{~b}$ & $68,16 \mathrm{~b}$ & $58,81 \mathrm{~b}$ \\
\hline F espaçamento & $4,9256^{*}$ & $20,8820^{* *}$ & $7,3443^{* *}$ \\
\hline F porta-enxerto x espacamento & $3,4582^{* *}$ & $1,3133^{\text {ns }}$ & $1,8882^{\mathrm{ns}}$ \\
\hline CV (\%) & 4,60 & 2,23 & 2,20 \\
\hline
\end{tabular}

Médias seguidas de, pelo menos, uma letra comum, para cada fator e variável, não diferem entre si, pelo teste de Tukey, ao nível de 5\% de probabilidade. $*$ significativo ao nível de $5 \%$ de probabilidade; ** significativo ao nível de $1 \%$ de probabilidade; ${ }^{\text {ns }}$ não-significativo.
TABELA 2- Luminosidade (L), Ângulo de cor (Hue) e Cromaticidade (C) externa e interna de pêssegos da cultivar Aurora-1, em função do porta-enxerto e do espaçamento entre plantas. Vista Alegre do Alto-SP, 2005.

\begin{tabular}{|c|c|c|c|c|c|c|}
\hline \multirow{2}{*}{ Porta-enxerto } & \multicolumn{3}{|c|}{ Coloração externa } & \multicolumn{3}{|c|}{ Coloração interna } \\
\hline & $\mathrm{L}$ & Hue & $\mathrm{C}$ & $\mathrm{L}$ & Hue & $\mathrm{C}$ \\
\hline 'Okinawa' semente & $61,68 \mathrm{a}$ & $71,87 \mathrm{a}$ & $40,05 \mathrm{a}$ & $73,10 \mathrm{a}$ & $97,26 \mathrm{a}$ & $56,45 \mathrm{~b}$ \\
\hline 'Okinawa' estaca herb. & $60,55 \mathrm{a}$ & $68,12 \mathrm{a}$ & $48,03 \mathrm{a}$ & $71,45 \mathrm{a}$ & $96,29 \mathrm{a}$ & $57,04 \mathrm{~b}$ \\
\hline 'Rigitano' & $62,95 \mathrm{a}$ & $73,22 \mathrm{a}$ & $48,92 \mathrm{a}$ & 71,81 a & $96,43 \mathrm{a}$ & $59,22 \mathrm{a}$ \\
\hline Clone 15 & $62,68 \mathrm{a}$ & $72,16 \mathrm{a}$ & $47,94 \mathrm{a}$ & $71,06 \mathrm{a}$ & $96,25 \mathrm{a}$ & $58,11 \mathrm{ab}$ \\
\hline Fporta-enxerto & $1,5481^{\text {ns }}$ & $1,8846^{\mathrm{ns}}$ & $0,6108^{\mathrm{ns}}$ & $2,6933^{\text {ns }}$ & $2,3968^{\mathrm{ns}}$ & $5,0464 * *$ \\
\hline \multicolumn{7}{|l|}{ Espaçamento } \\
\hline $6 \times 2 \mathrm{~m}$ & $62,05 \mathrm{a}$ & $71,54 \mathrm{a}$ & $48,20 \mathrm{a}$ & $71,99 a$ & $96,18 \mathrm{a}$ & $58,16 \mathrm{ab}$ \\
\hline $6 \times 3 \mathrm{~m}$ & $62,39 \mathrm{a}$ & $71,74 \mathrm{a}$ & $49,06 \mathrm{a}$ & $71,56 \mathrm{a}$ & $96,43 \mathrm{a}$ & $58,32 \mathrm{a}$ \\
\hline $6 \times 4 \mathrm{~m}$ & $61,46 \mathrm{a}$ & $70,75 \mathrm{a}$ & 48,21 a & $72,02 \mathrm{a}$ & $97,07 \mathrm{a}$ & $56,64 \mathrm{~b}$ \\
\hline F espaçamento & $0,3863^{\text {ns }}$ & $0,1387^{\mathrm{ns}}$ & $0,5891^{\text {ns }}$ & $0,3063^{\text {ns }}$ & $2,9342^{\mathrm{ns}}$ & $3,8338^{*}$ \\
\hline F porta-enxerto x espaçamento & $1,6187^{\text {ns }}$ & $1,5993^{\mathrm{ns}}$ & $2,3934^{*}$ & 4,0790 ** & $1,3790^{\mathrm{ns}}$ & $2,0737^{\text {ns }}$ \\
\hline $\mathrm{CV}(\%)$ & 4,90 & 7,87 & 5,30 & 2,61 & 1,10 & 3,26 \\
\hline
\end{tabular}

Médias seguidas de, pelo menos, uma letra comum, para cada fator e variável, não diferem entre si, pelo teste de Tukey, ao nível de $5 \%$ de probabilidade.* significativo ao nível de 5\% de probabilidade; ** significativo ao nível de $1 \%$ de probabilidade; ${ }^{\text {ns }}$ não-significativo.

TABELA 3 - Firmeza $(\mathrm{N})$, teor de sólidos solúveis (SS), acidez titulável (AT) e relação SS/AT de pêssegos da cultivar Aurora-1, em função do porta-enxerto e do espaçamento entre plantas. Vista Alegre do Alto-SP, 2005

\begin{tabular}{ccccc}
\hline Porta-enxerto & Firmeza & SS & AT & SS/AT \\
\hline 'Okinawa' semente & $20,80 \mathrm{a}$ & $12,33 \mathrm{bc}$ & $0,38 \mathrm{a}$ & $32,90 \mathrm{ab}$ \\
'Okinawa' estaca herb. & $19,23 \mathrm{a}$ & $12,10 \mathrm{c}$ & $0,40 \mathrm{a}$ & $30,57 \mathrm{~b}$ \\
'Rigitano' & $19,13 \mathrm{a}$ & $12,67 \mathrm{ab}$ & $0,38 \mathrm{a}$ & $33,81 \mathrm{ab}$ \\
Clone 15 & $18,44 \mathrm{a}$ & $12,95 \mathrm{a}$ & $0,39 \mathrm{a}$ & $34,02 \mathrm{a}$ \\
\hline F porta-enxerto & $0,8084^{\text {ns }}$ & $8,3423^{* *}$ & $1,6744^{\text {ns }}$ & $3,3851^{*}$ \\
\hline Espaçamento & & & & \\
\hline $6 \times 2 \mathrm{~m}$ & $19,82 \mathrm{a}$ & $11,81 \mathrm{c}$ & $0,40 \mathrm{a}$ & $30,08 \mathrm{~b}$ \\
$6 \times 3 \mathrm{~m}$ & $18,93 \mathrm{a}$ & $12,58 \mathrm{~b}$ & $0,38 \mathrm{a}$ & $33,36 \mathrm{a}$ \\
$6 \times 4 \mathrm{~m}$ & $19,42 \mathrm{a}$ & $13,14 \mathrm{a}$ & $0,38 \mathrm{a}$ & $35,04 \mathrm{a}$ \\
\hline F espacamento & $0,2528^{\text {ns }}$ & $35,0140^{* *}$ & $2,1874^{\mathrm{ns}}$ & $11,5466^{* *}$ \\
\hline F porta-enxerto x espacamento & $0,5007^{\text {ns }}$ & $3,4489^{* *}$ & $4,4404^{* *}$ & $5,2657^{* *}$ \\
\hline CV $(\%)$ & 19,79 & 3,61 & 7,22 & 9,05 \\
\hline
\end{tabular}

Médias seguidas de, pelo menos, uma letra comum, para cada fator e variável, não diferem entre si, pelo teste de Tukey, ao nível de 5\% de probabilidade. $*$ significativo ao nível de $5 \%$ de probabilidade; ** significativo ao nível de $1 \%$ de probabilidade; ${ }^{\text {ns }}$ não-significativo. Firmeza expressa em N; SS expressa em ${ }^{\circ}$ Brix; AT expressa em g de ácido cítrico $100^{-1}$. 


\section{CONCLUSÕES}

1- Os porta-enxertos e espaçamentos estudados não influenciaram na coloração externa, no ângulo de cor e na luminosidade do mesocarpo, na firmeza e na acidez dos pêssegos 'Aurora-1'.

2- Pêssegos 'Aurora-1' apresentaram maior massa fresca, diâmetros longitudinal e equatorial quando se utiliza o Clone 15 ou a cultivar Rigitano de umezeiro como porta-enxerto.

3- O uso do Clone 15 de umezeiro como porta-enxerto induziu à produção de frutos com maior teor de sólidos solúveis e melhor índice de maturação, em relação ao 'Okinawa' propagado por estacas herbáceas.

4- O maior espaçamento entre plantas $(6 \times 4 \mathrm{~m})$ induziu à produção de pêssegos menores, mas com maior teor de sólidos solúveis e maior relação $\mathrm{SS} / \mathrm{AT}$.

\section{AGRADECIMENTOS}

Os autores agradecem à FAPESP (Processos n ${ }^{\text {os }}$ 04/121106 e 05/50157-7) e ao Sr. Valdenir Rossi, proprietário da Fazenda Santa Alzira (Vista Alegre do Alto-SP), pelo apoio.

\section{REFERÊNCIAS}

AGRIANUAL. Pêssego. São Paulo: FNP Consultoria e Comércio, 2007. p.436-442.

AL-JALEEL, A.; ZEKRI, M.; HAMMAM, Y. Yield, fruit quality, and tree health of 'Allen Eureka' lemon on seven rootstocks in Saudi Arabia. Journal of the American Society for Horticultural Science, Alexandria, v.105, p.457-465, 2005

ALMEIDA, G.V.B. de. Características qualitativas de pêssegos produzidos em Paranapanema-SP, safra 2005, e sua valoração no mercado atacadista de São Paulo. 2006. 66f. Dissertação (Mestrado em Agronomia-Produção Vegetal) - Faculdade de Ciências Agrárias e Veterinárias, Universidade Estadual Paulista, Jaboticabal, 2006.

AOAC. Official methods of analysis of the Association of Analytical Chemists. $13^{\text {th }}$ ed. Washington: Ed. Patrícia Cunniff, 1997. 1018p.

BARBOSA, W.; CAMPO DALL'ORTO, F.A.; OJIMA, M.; NOVO, M.do.C.de.S.S.; CARELLI, M.L.C.; FILHO, J.A.de.A. O pessegueiro em pomar compacto: $\mathrm{x}$. comportamento de cultivares e seleções sob poda de encurtamento dos ramos pós-colheita. Bragantia, Campinas, v.59, n.2, p.197-203, 2000

CAMPO DALL'ORTO, F.A.; OJIMA, M.; BARBOSA, W.; MARTINS, F.P.; RIGITANO, O. Clones de ameixeira como portaenxerto ananicante para pessegueiro. Boletim Técnico IAC, n. 122,1988
CAMPO DALL'ORTO, F.A.; OJIMA, M.; BARBOSA, W.; MARTINS, F.P. O nanismo do pessegueiro induzido pela enxertia no damasqueiro-japonês. Pesquisa Agropecuária Brasileira, Brasília, v.27, n.3, p.517-521, 1992.

CAMPO-DALL'ORTO, F.A.; OJIMA, M.; BARBOSA, W.; TOMBOLATO, A.F.C.; RIGITANO, O., ALVES, S. Cultivo de seleções de pessegueiros precoces no sistema de pomar compacto com poda drástica anual de renovação da copa. Pesquisa Agropecuária Brasileira, Brasília, v.19, n.6, p.719-727, 1994.

CASTLE, W.S. Rootstock as a fruit quality factor in citrus and deciduos tree crops. New Zealand Journal of Crop and Horticultural Science, Wellington, v.23, p.383-394, 1995.

CHITARRA, M.I.F.; CHITARRA, A.B. Pós-colheita de frutos e hortaliças: fisiologia e manuseio. Lavras: ESAL-FAEPE, 2005, $785 \mathrm{p}$.

CQH-CEAGESP. Centro de Qualidade em Horticultura Companhia de Entreposto e Armazéns Gerais de São Paulo. 1998. Classificação de pêssego e nectarina. São Paulo. 2000. Folder. Programa Brasileiro para a melhoria dos Padrões Comerciais e Embalagens de Hortigranjeiros.

DENARDI, F.; SPENGLER, M.M. Comportamento da cultivar macieira Fuji (Malus domestica, Borkh) sobre três diferentes porta-enxertos. Revista Brasileira de Fruticultura, Jaboticabal, v.23, n.3, p.630-633, 2001.

ESTAT. Sistema para análises estatísticas (v. 2.0). Jaboticabal: Departamento de Ciências Exatas, FCAV-UNESP, 1994

FAO. Melocotones y Nectarinas: producción, área y rendimiento. 2007. Disponível em: <http://www.faostat.fao.org/site/408/ DesktopDefault.aspx?PageID=408>. Acesso em: 26 mar. 2007.

FORNER-GINER, M.A.; ALCAIDE, A.; PRIMO-MILLO, E.; FORNER, J.B. Performance of 'Navelina' orange on 14 rootstocks in Northern Valencia (Spain). Journal of the American Society for Horticultural Science, Alexandria, v.98, p.223-232, 2003.

GIORGI, M.; CAPOCASA, F.; SCALZO, J.; MURRI, G.; BATTINO, M.; MEZZETTI, B. The rootstock effects on plant adaptability, production, fruit quality, and nutrition in the peach (cv. 'Suncrest'). Journal of the American Society for Horticultural Science, Alexandria, v.107, p. 36-42, 2005.

KADER, A.A. Postharvest technology of horticultural crops. Oakland: University of California, Agriculture and Natural Resources, 2002.535p.

MINOLTA CORP. Precise color communication: color control from feeling to instrumentation. Ramsey: Minolta Corporation Instrument Systems Division, 1994. 49p. 
OJIMA, M.; CAMPO DALL'ORTO, F.A.; BARBOSA, W.; MARTINS, F.P.; SANTOS, R.R. dos; RIGITANO, O. 'Aurora-1'e 'Aurora-2': novas cultivares de pêssego doce de polpa amarela. In: CONGRESSO BRASILEIRO DE FRUTICULTURA, 10., 1989, Fortaleza. Anais... Fortaleza: SBF, 1989. p.422-425.

OLIVEIRA, J.B. de; CAMARGO, M.N.; ROSSI, M.; CALDERANO-FILHO, B. Mapa pedológico do Estado de São Paulo: legenda expandida. Campinas: Instituto Agronômico; Rio de Janeiro: Embrapa-Solos, 1999. 64p.

PEREIRA, F.M.; NACHTIGAL, J.C.; ROBERTO, S.R. Tecnologia para a cultura do pessegueiro em regiões tropicais e subtropicais. Jaboticabal: Funep, 2002. 62p.

PEREIRA, F.M.; MAYER, N.A. Pessegueiro: tecnologias para a produção de mudas. Jaboticabal: Funep, 2005. 65p.
PEREIRA, F.M.; MAYER, N.A.; CAMPO DALL'ORTO, F.A. 'Rigitano': nova cultivar de umezeiro para porta-enxerto de pessegueiro. Revista Brasileira de Fruticultura, Jaboticabal, v.29, n.1, p.172-175, 2007.

PEREZ-PEREZ, J.G.; CASTILLO, I.P.; GARCIA-LIDON, A.; BOTIA, P.; GARCIA-SANCHEZ, F. Fino lemon clones compared with the lemon varieties Eureka and Lisbon on two rootstocks in Murcia (Spain). Journal of the American Society for Horticultural Science, Alexandria, v.106, p.530-538, 2005.

SATO, G.S. Produção de pêssegos de mesa e para indústria no Brasil. Informações Econômicas, São Paulo, v.31, n.6, p.61-63, 2001.

TSIPOURIDIS, C.; THOMIDIS, T. Effect of 14 peach rootstocks on the yield, fruit quality, mortality, girth expansion and resistance to frost damages of May Crest peach variety and their susceptibility on Phytophthora citrophthora. Journal of the American Society for Horticultural Science, Alexandria, v.103, p.421-428, 2005. 